Reprod. Nutr. Dévelop., 1988, 28 (2 B), 459-472.

\title{
Characteristics of the melatonin signal that provide the photoperiodic code for timing seasonal reproduction in the ewe
}

\author{
F. J. KARSCH, B. MALPAUX, Nancy L. WAYNE, Jane E. ROBINSON
}

Reproductive Endocrinology Program, Consortium for Research in Developmental and Reproductive Biology, and Department of Physiology, The University of Michigan, Ann Arbor, MI USA 48109-0404.

\begin{abstract}
Summary. The following is a progress report of our studies to identify important features of the circadian pattern of melatonin secretion which provide the photoperiodic code for daylength in regulating seasonal breeding in the Suffolk ewe. The first series of experiments evaluated two conceptual models of how melatonin codes for daylength : the circadian timing of the melatonin elevation as opposed to the length of the time melatonin is elevated during each 24-hr period (phase vs duration). Strong support has been gathered for the duration hypothesis. No evidence was obtained to support a role for phase ; nevertheless, this hypothesis could not be discounted definitively. A second series of studies evaluated the importance of the previous melatonin pattern to the interpretation of a given melatonin signal. Evidence is presented that a fixed melatonin pattern can maintain a given reproductive response only for a limited length of time and that this response can be prolonged by appropriate changes in the melatonin pattern. Thus, change is an important feature of the melatonin signal. Further, the nature of the melatonin change appears to be crucial, specifically whether the nocturnal elevation increases or decreases in duration. Thus, transfer to a common photoperiod can promote either reproductive induction or arrest, depending upon whether the transfer leads to a decrease or increase in daylength. This has important ramifications to the photoperiodic timekeeping process in those species of mammals which utilize daylength to time their seasonal reproductive cycle.
\end{abstract}

\section{Introduction.}

The importance of the pineal gland in mediating the effects of photoperiod on timing the seasonal reproductive cycle of mammals is firmly established (Reiter, 1980 ; Bittman, 1984 ; Lincoln, 1984). Further, it is clear that this role of the pineal is enforced through its rhythmic secretion of melatonin, a hormone secreted principally at night. A generalized scheme for this seasonal timekeeping process in sheep is illustrated in figure 1. According to this scheme, the alternating long and short photoperiods of summer and winter modulate the characteristics of the melatonin rhythm and this determines the timing of seasonal 
fluctuation in a host of physiological functions, including reproduction. We have now come to realize that photoperiod does not normally drive the seasonal breeding pattern of the ewe. Rather, seasonality results from an endogenous reproductive rhythm, with photoperiod acting through melatonin to time this process. This ensures appropriate phasing of the annual reproductive and environmental cycles (for details see Robinson and Karsch, 1988).

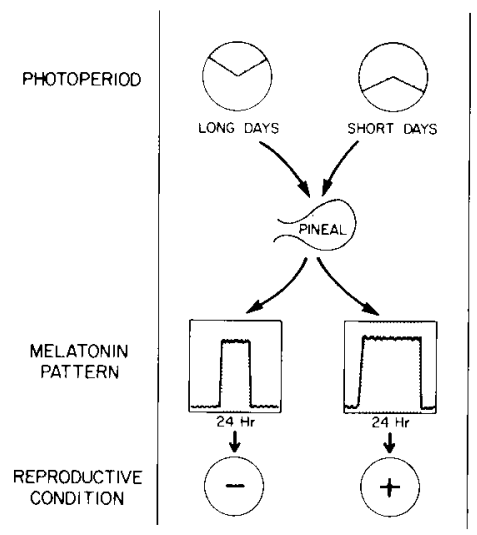

FIG. 1. - Involvement of melatonin in timing seasonal reproduction in sheep.

The realization that the 24 -hr pattern of melatonin secretion provides a neuroendocrine code for daylength has stimulated an area of investigation to identify those characteristics of the melatonin signal which convey the photoperiod message. The present report outlines our progress in evaluating two issues pertaining to the melatonin signal in the Suffolk ewe : 1) the importance of the circadian timing of the melatonin elevation as opposed to the length of time that melatonin is secreted during each 24 -hr period (phase vs duration) ;2) the importance of the previous melatonin pattern to the interpretation of a given melatonin signal. The fundamental relationship between these two issues is then considered.

\section{Experimental model.}

To identify important characteristics of the melatonin pattern, we have utilized a traditional endocrine approach - removal of the gland followed by replacement of the hormone of interest. For this purpose, Suffolk ewes were pinealectomized and then equipped with a portable back-pack infusion device. The device contained a programmable pump for intravenous infusion which allowed any desired circadian pattern of melatonin to be generated for any length 
of time (over a year in some studies). The artificially-produced serum melatonin levels were determined to be physiological (by radioimmunoassay). The effect of treatment on reproductive condition was monitored by determining responsiveness to the negative feedback effects of estradiol on gonadotropin secretion. For this purpose, each ewe was ovariectomized and treated with a constant-release Silastic estradiol implant (OVX $+E$ ewes). This maintained a physiological serum estradiol concentration $(\sim 3 \mathrm{pg} / \mathrm{ml})$, thus providing a fixed negative feedback signal to the hypothalamo-pituitary axis (Legan et al., 1977). Changes in reproductive state were evaluated from serum concentrations of luteinizing hormone (LH). Periods of elevated $\mathrm{LH}$ are indicative of the breeding season : low LH signifies anestrus. Earlier studies have shown that changes in $\mathrm{LH}$ in OVX + E ewes provide a robust, easily measured, and photoperiodically sensitive indicator of seasonal reproductive state (Legan et al., 1977 ; Legan and Karsch, 1980 ; Karsch et al., 1984).

\section{Phase vs duration.}

Attempts to identify the feature(s) of the melatonin pattern critical to the measurement of daylength have focused on two conceptual models : phase and duration (Goldman et al., 1982 ; Stetson and Watson-Whitmyre, 1986). According to the phase hypothesis, there is a circadian rhythm of sensitivity to melatonin and determination of a particular reproductive response depends upon the coincidence of elevated melatonin secretion with the sensitive period. Thus, as photoperiod changes throughout the year, so does the phase relationship between the circadian rhythms of melatonin secretion and the sensitive period. This leads to seasonal changes in reproductive state. According to the duration hypothesis, the length of time that melatonin is elevated during each 24-hr period is proportional to the length of the night, and reproductive condition is dependent upon this interval. Thus, as daylength changes during the year, so does the duration of the circadian melatonin rise, and it is this which regulates timing of the breeding season.

Distinction between these models has been a topic of considerable interest and debate. Three lines of evidence have been obtained which suggest that duration is critical in the ewe. First, the duration of the nocturnal melatonin rise is indeed proportional to the length of the night (Rollag et al., 1978 ; Arendt et al., 1981 ; Kennaway et al., 1983 ; Robinson and Karsch, 1987). This is a necessary condition for the duration hypothesis, but in itself does not provide empirical support. The second line of evidence was obtained using the melatonin delivery system described above. In particular, we have systematicaliy varied the duration of the nightly melatonin rise in pinealectomized ewes and have found, in three separate studies, that the reproductive state invariably conformed to the length of time that melatonin was elevated each $24 \mathrm{~h}$ (Bittman and Karsch, 1984 ; Yellon et al., 1985). 
Results from one such study are shown in figure 2 (for clarity, results for several control groups are not illustrated but can be found in the original report, see figure 3 in Bittman and Karsch, 1984). Prior to day 0 of the study, two groups of pinealectomized ewes were maintained in long days (16L : 8D) ; each night the ewes were infused with a melatonin pattern which mimicked that generated endogenously under the long photoperiod ( $8 \mathrm{hr}$ infusion during $8 \mathrm{hr}$ night). This was found to be an inhibitory signal and to suppress $\mathrm{LH}$ to undetectable levels (for this response see figure 2 in Bittman and Karsch, 1984). On day 0, both groups of ewes were transferred to short days (8L : 16D). At the same time, the duration of the nightly melatonin infusion in one group was changed to match the short photoperiod (16 hr infusion during $16 \mathrm{hr}$ night). This led to reproductive induction and $\mathrm{LH}$ increased (figure 2, left). In the other group, the long-day pattern of melatonin was maintained following transfer to short days, thus producing a mismatch between the duration of the melatonin infusion and the duration of the night. This maintained reproductive suppression and $\mathrm{LH}$ remained low (figure 2, right).

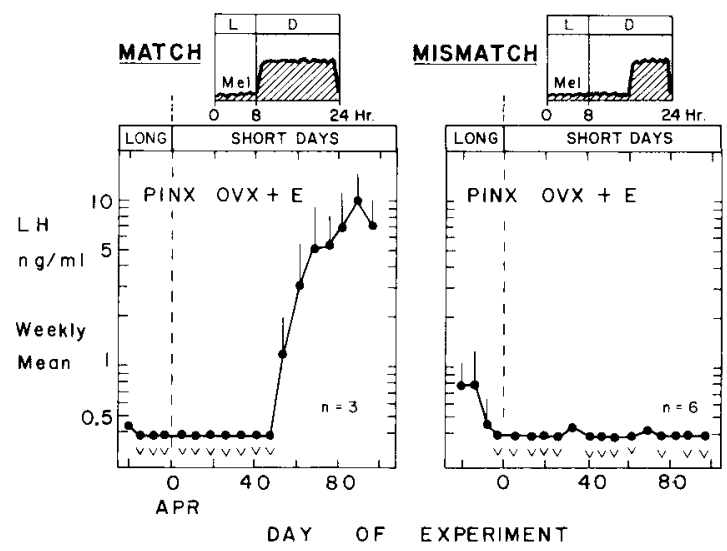

FIG. 2. - Mean (+ SEM) serum LH concentration in pinealectomized (PINX) OVX + 4 ewes in which photoperiod and melatonin (Mel) were either matched (left, short-day Mel in short days of 8L : 16D) or mismatched (right, long-day Mel in short days) beginning on day 0 . Before day 0, a long-day Mel pattern was infused in long days (16L: 8D) to suppress $\mathrm{LH}$ values (presented as weekly mean of twice weekly samples). Number of ewes given by $n ; v$ signifies undetectable. The light (L)/dark (D) cycle and pattern of melatonin infused after day 0 are shown by key at top. From Karsch et al. (1984) and Bittman and Karsch (1984).

The salient finding of this study, and the others in which duration of the melatonin elevation was systematically varied, is that the reproductive condition invariably conformed to the length of time that melatonin was elevated during each 24-hr period (Bittman and Karsch, 1984 ; Yellon et al., 1985). Although these findings are clearly consistent with the duration hypothesis, they do not discount phase because at least a portion of the artificially-produced melatonin rise invariably overlapped with the night, and thus could have coincided with a phase of responsiveness to melatonin. 
The third and more powerful line of support for the duration hypothesis was obtained from a recent study (Wayne et al., 1988) in which duration of the melatonin infusion was held constant and its phase varied with respect to the light/dark cycle. This approach was based on the expectation that, if a circadian rhythm of sensitivity exists and is entrained by the light/dark cycle, it should be possible to miss the sensitive phase by altering the timing of the infusion, and this would eliminate the reproductive response. On the other hand, if duration is crucial, the circadian timing of the melatonin elevation should be inconsequential to the reproductive response. A detailed report of this study is presented elsewhere (Wayne et al., 1988) ; a brief synopsis of it is now provided.

The study consisted of 3 groups of pinealectomized ewes (fig. 3) which initially were reproductively suppressed by nightly infusion of a long-day pattern of melatonin under long days ( $8 \mathrm{hr}$ infusion during $8 \mathrm{hr}$ night). Once low LH levels were established, the infusion was terminated in one group to determine the response to removal of the inhibitory signal (STOP MEL group). The second group continued to receive the 8-hr melatonin infusion during the 8-hr night (NIGHT MEL group). In the third group, the 8-hr infusion was phase-shifted by 12 hours such that melatonin was given in the middle of the 16-hr day (DAY MEL group). Following termination of the long-day pattern of melatonin, $\mathrm{LH}$ increased after a lag of about 90 days. In marked contrast, LH remained suppressed in all ewes which continued to receive the long-day pattern of melatonin, regardless of whether the infusion was given at night or during the middle of the 16-hr day (fig. 3).

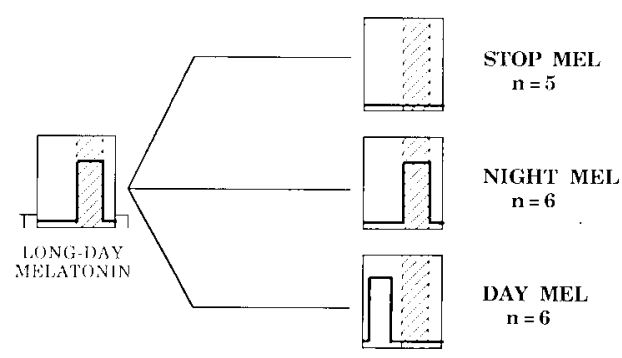

FIG. 3. - Test of phase-duration hypotheses. Each box describes melatonin pattern (solid line) relative to dark period (shading). $\mathrm{n}$ is number of ewes, From Wayne et al. (1988).

These observations fail to support the phase hypothesis and suggest that duration is critical, regardless of the time of day that melatonin is elevated. This conclusion, however, must be tempered by two reservations, and so it is not possible to discount phase. First, the putative melatonin sensitive period might be rather broad and extend into the day, in which case our 8-hr infusion in the middle of the 16-hr day may not have missed it. Second, it could be argued that the circadian rhythm of sensitivity to melatonin is not entrained by the light/dark cycle, but by some other cyclic variable such as the melatonin rhiythm itself (Stetson et al., 1986a). Despite these reservations, it should be stressed that we 
are not aware of any experimental support for the phase hypothesis in sheep. Available evidence clearly points to duration.

Support for the phase hypothesis has been obtained primarily in two photoperiodic rodents, the Syrian and Djungarian hamster (Watson-Whitmyre and Stetson, 1983 ; Stetson and Watson-Whitmyre, 1986 ; Stetson et al., 1986a). In those studies, the effectiveness of daily or twice daily injections of melatonin in eliciting a reproductive response depended upon the circadian timing of the injections. Effective times appeared to be near the light/dark transitions. It is important to note, however, that not all injection studies in Syrian hamsters have produced such results (Tamarkin et al., 1977 ; Watson-Whitmyre and Stetson, 1983). Further, other studies in Djungarian hamsters have yielded results which are inconsistent with the phase hypothesis (Carter and Goldman, 1983 ; Goldman et al., 1984). In those experiments, melatonin was infused into pinealectomized Djungarian hamsters in paradigms similar to our infusion studies in the ewe. Both the phase and the duration of the infusion were systematically varied such that virtually all phases of the light/dark cycle were probed for a melatonin-sensitive phase. In all circumstances, the duration of the melatonin infusion was found to be the critical variable ; its timing with respect to the light/dark cycle appeared to be irrelevant. Recent observations in another photoperiodic rodent, the whitefooted mouse, are consistent with this finding (Dowell and Lynch, 1987).

It is important to stress that the experiments in hamsters are subject to alternative interpretations. For example, the physiological relevance of the injection studies which support phase may be questioned on the basis of the dose of melatonin and the absence of a description of the resulting patterns and levels of melatonin in the circulation. In this regard, microgram quantities were provided as daily or twice-daily boluses compared to low nanogram quantities calculated to be the normal amount secreted during a 24-hr period and found effective in the infusion studies (Carter and Goldman, 1983). Interpretation of the infusion studies, which support duration, is clouded by one of the reservations described above for our infusion experiments in sheep, namely the melatonin treatment itself might entrain a circadian rhythm of sensitivity to melatonin (Stetson et al., 1986a). Other experimental approaches which should help clarify this issue include resonance and T-cycle infusion paradigms for melatonin ; such studies are currently in progress in the Djungarian hamster (Darrow, Bartness, Elliott, Goldman, unpublished). The approaches might also address another important issue, namely whether a circadian oscillator is involved in the measurement of melatonin duration.

Given the available information, what can we conclude with regard to the characteristics of the melatonin pattern which provide the code for daylength in the ewe ? Clearly, an important role for duration is implicated. However, we have not yet been able to test phase definitively and this reflects limitations in our current methodologies for assaying melatonin responsiveness and in our current level of understanding of the mode of action of melatonin. If, however, there is a circadian rhythm of sensitivity to melatonin, it would seem unlikely that it is entrained by the light/dark cycle. 


\section{Prior exposure to melatonin.}

It is well established that the reproductive response to a given daylength in a variety of seasonal breeders is dependent upon prior photoperiodic exposure, often referred to as " photoperiodic history ". Further, this appears to be due to an influence of the previous melatonin pattern on the response to a subsequent melatonin signal. In this context, therefore, prior melatonin exposure, and changes in its pattern, become important to our consideration of the nature of the signal.

Photorefractoriness. - One manifestation of the importance of photoperiodic history is the inability of many photoperiodic species to respond to a fixed daylength indefinitely. Ultimately, the reproductive condition shifts, a phenomenon referred to as photorefractoriness. In sheep, refractoriness is expressed both during prolonged exposure to day!engths which were initially inhibitory (in which case animals eventually enter the breeding season) and during extended exposure to daylengths which were initially inductive (in which case animals ultimately undergo reproductive arrest) (Lincoln, 1980; Almeida and Lincoln, 1984 ; Robinson and Karsch, 1984 ; Robinson et al., 1985 ; Karsch et al., 1986). The photoneuroendocrine basis of refractoriness is of considerable interest with respect to the development of practical approaches to regulating fertility using light or melatonin, and also with respect to understanding the temporal organization of the natural seasonal reproductive cycle.

Our initial approach to investigating the basis of photorefractoriness has been to determine whether the condition reflects an alteration in the pre- or the postpineal processing of the photoperiodic message. Specifically, we have evaluated whether there is an alteration in the generation of the melatonin signal, or in the responsiveness to melatonin, as photorefractoriness develops. Our initial series of studies dealt with refractoriness to an inductive daylength.

The upper panel of figure 4 illustrates the reproductive response (pattern of serum $\mathrm{LH}$ ) in pineal-intact $\mathrm{OVX}+\mathrm{E}$ ewes during prolonged exposure to inductive short days. Following transfer from long to short days on day $0(16 \mathrm{~L}: 8 \mathrm{D}$ to $8 \mathrm{~L}: 16 \mathrm{D})$, the mean serum $\mathrm{LH}$ concentration remained low for some 50 days, increased dramatically to a maximum around day 70 , remained elevated until day 110 , and then fell precipitously to reach an undetectable level by day 150 . This typifies the pattern of reproductive induction and eventual development of refractoriness which we have observed on numerous occasions following transfer of ewes from long to short days.

The lower panel of figure 4 illustrates the results of our initial test of whether refractoriness to inductive photoperiod can be accounted for by the loss of response to a short-day pattern of melatonin. For this purpose, pinealectomized ewes were equipped with the infusion device and treated initially with a long-day pattern of melatonin ( $8 \mathrm{hr}$ each night) to suppress LH. The infusion was then switched to a short-day pattern (16 hr infusion during $16 \mathrm{hr}$ nights) and this was maintained for an interval sufficient for development of short-day refractoriness in 


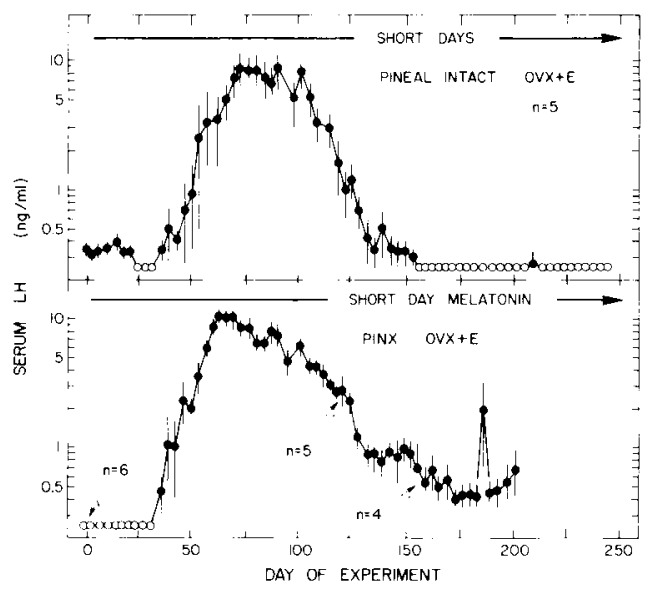

FIG. 4. - Mean ( \pm SEM) serum LH concentration (twice weekly samples) in pineal-intact OVX $+E$ ewes during prolonged exposure to a short photoperiod of $8 L: 16 D$ (top) and in pinealectomized (PINX) ewes during prolonged infusion of a short-day pattern of melatonin (16 hr each night) (bottom). Prior to day 0 , ewes were exposed to a long photoperiod or infused with a long-day pattern of melatonin to suppress LH. Open circles depict undetectable values ; n depicts number of ewes (two infused ewes died resulting in the changes of $n$ ). Redrawn from Karsch et al. (1986).

pineal-intact ewes. As illustrated in figure 4, the time course of the LH response in pinealectomized ewes during infusion of the short-day pattern of melatonin (lower panel) was much the same as that in pineal-intact ewes maintained on the fixed short photoperiod (upper panel). Although there were some minor quantitative differences, it is important to emphasize that all pinealectomized ewes appeared to become unresponsive to a melatonin pattern which was once inductive. This study was subsequently repeated with similar results (Wayne et al., 1986).

In a separate experiment, we monitored the circadian patterns of circulating melatonin during the course of reproductive induction and the subsequent development of refractoriness following transfer of pineal-intact ewes from long to short days (Malpaux et al., 1987). Hourly samples were obtained for 24 or $48 \mathrm{hr}$ intervals approximately every 2 weeks following the light shift. Once the melatonin pattern stabilized by day 8 after the shift from long to short days, no further change was observed in the duration of the melatonin elevation or in its phase relative to the light/dark cycle. Regardless of the stage of the reproductive response, includin the melatonin signal itself. In an parallel series of studies using the same throughout the night (fig. 5).

The preceding series of experiments provides compelling support for the conclusions that refractoriness to an inductive daylength results from a change in the post-pineal processing of the photoperiodic message rather than an alteration in the melatonin signal itself. In an parallel series of studies using the same approaches of melatonin infusion and characterization of melatonin secretory profiles, we are gathering evidence that the same holds true for refractoriness to an inhibitory photoperiod (Wayne et al., 1988 ; Malpaux et al., 1988a). 

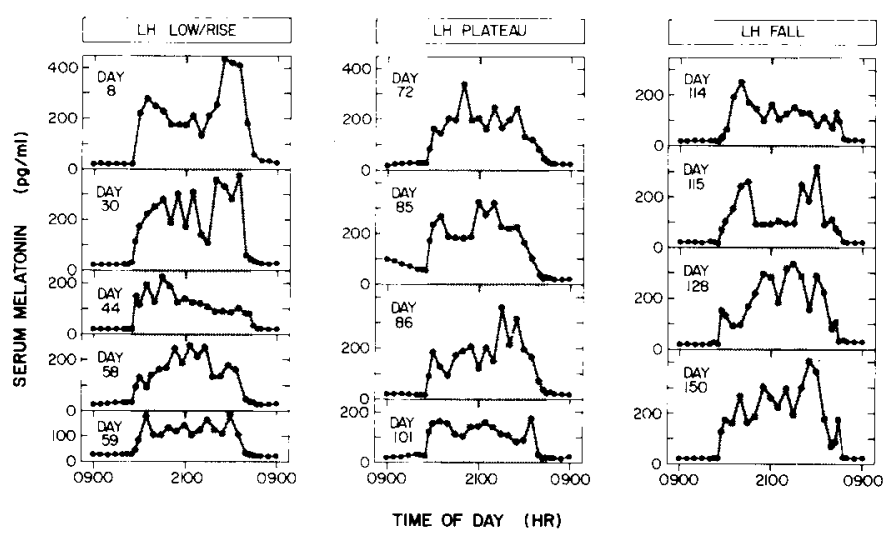

FIG. 5. - Mean serum concentrations of melatonin during individual 24-hr periods of hourly sampling in 4 pineal-intact OVX $+E$ ewes at various times following transfer from long to short days (16L : 8D to 8L : 16D). Day after light shift is given in each box. Data are oriented with respect to various stages of the reproductive response as indicated in the upper portion of the figure. The LH-response pattern in these ewes was virtually identical to that illustrated in the upper panel of figure 4 . Shaded areas indicate dark period $(1300 \mathrm{~h}-0500 \mathrm{~h})$. For clarity, variability among ewes is not shown. From Malpaux et al. (1987).

Change. - A somewhat different issue with regard to the melatonin signal and photorefractoriness pertains to the role of change in photoperiodic signalling. In this regard, it is important to note that the preceding experiments all utilized single-step changes in daylength or melatonin patterns, followed by constant conditions for prolonged periods. We have recently observed that the development of refractoriness to a short photoperiod can be delayed by a further reduction in daylength (Malpaux et al., 1988b). For example, a two-step drop from 16- to 12- to 8-hr of light/day, with the second reduction applied 55 days after the first, led to a marked prolongation of the LH elevation compared to that in ewes exposed to single-step decreases in daylength of 16-12 or 16-8 hr of light/day (fig. 6). This prolongation was the result of the two-step drop and not

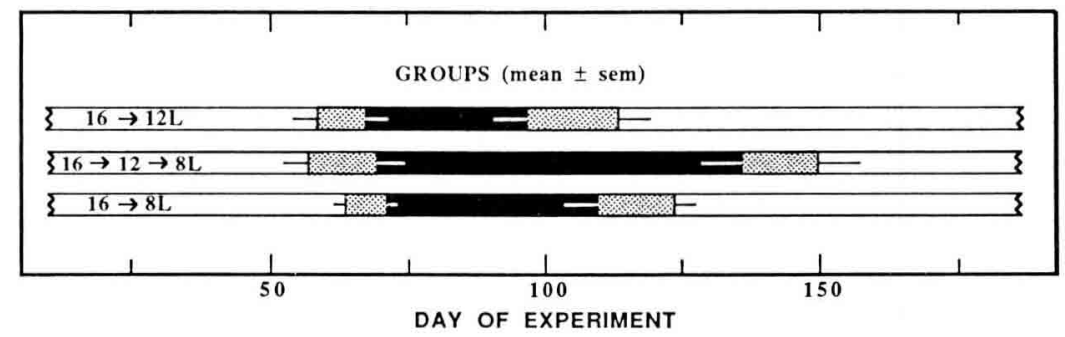

FIG. 6. - Length of $\angle H$ elevation in $O V X+E$ ewes exposed to single-step drop in daylength (from 16 to $12 \mathrm{hr}$ light/day or from 16 to $8 \mathrm{hr}$ light/day) or to a two-step drop from 16 to 12 to $8 \mathrm{hr}$ light/day. Black areas are times of maximal LH values; areas on either side of black bars are times $\mathrm{LH}$ was increasing or decreasing ; LH was basal at other times. From Malpaux et al. (1988b). 
the final daylength attained. Further, the two-step decrement in daylength produced a step-wise increment in duration of the nocturnal melatonin rise (data not shown). This leads to the hypothesis that change, in itself, is an important characteristic of the melatonin signal and introduces the final topic to be considered in this report - direction of change in photoperiod.

Direction of photoperiodic change. - Experiments in the Japanese quail provided the first demonstration that a given photoperiod can be either inductive or inhibitory depending upon photoperiodic history and thus whether daylength increases or decreases (Robinson and Follett, 1982). The importance of photoperiodic history and direction of change in daylength has since been demonstrated in a number of seasonally breeding mammals including the wild European rabbit (Boyd, 1986), several photoperiodic rodents (Horton, 1984 ; Stetson et al., 1986b ; Hoffmann et al., 1986), and the sheep (Robinson and Karsch, 1987). The studies in sheep are of particular interest with regard to the critical features of the melatonin signal because the 24-hr patterns of circulating melatonin were monitored. These studies are now summarized; further details are described elsewhere (Robinson and Karsch, 1987).

Pineal-intact OVX $+\mathrm{E}$ ewes were transferred to an equinoctial photoperiod of 13L : 11D (includes $1 \mathrm{hr}$ for civil twilight) following prior exposure to either 16L : 8D or 10L : 14D (solstice photoperiods at the site of the study in Ann Arbor, Michigan). The 3-hr reduction in daylength from 16 to $13 \mathrm{hr}$ of light/day was regarded as inductive and elicited an increase in serum $\mathrm{LH}$ concentrations. In

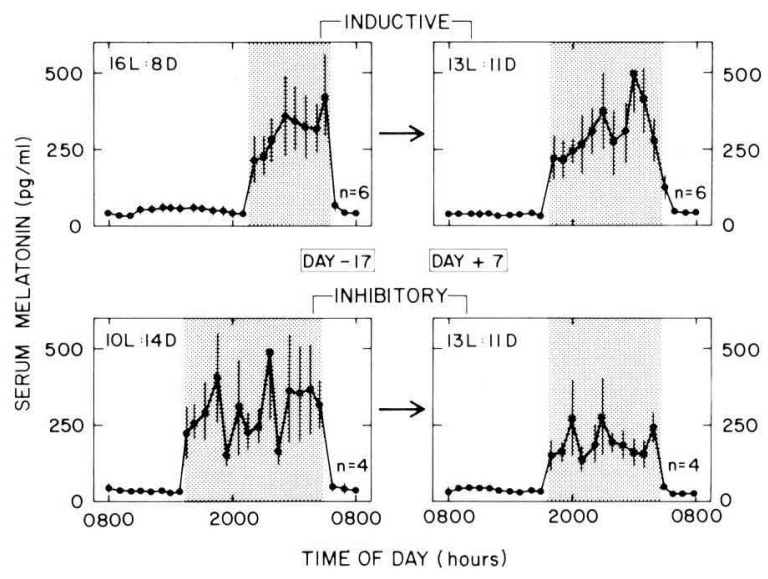

FIG. 7. - Mean ( \pm SEM) serum concentrations of melatonin during 24-hr periods of hourly sampling in two groups of pineal-intact OVX $+E$ ewes 17 days before (left) and 7 days after (right) transfer from solstice daylengths to a common intermediate photoperiod (13L : 11D). Top panels show melatonin before and after a 3-hr photoperiodic decrease, a treatment which led to reproductive induction. Bottom panels show melatonin before and after a 3-hr increase in daylength which inhibited reproduction. Shaded areas indicate darkness; $n$ depicts number of ewes. Melatonin patterns on days 41 and 81 after the light shift were essentially the same as those on day 7 (not shown). From Robinson and Karsch (1987). 
contrast, the 3-hr increase in daylength from 10 to $13 \mathrm{hr}$ of light/day was interpreted as inhibitory and promoted a decrease in circulating $\mathrm{LH}$. The shift to the common intermediate photoperiod thus provided either an inductive or inhibitory signal, depending upon whether daylength had increased or decreased. Under these circumstances, the direction of change appeared to be more critical than the absolute length of the day, a possibility suggested previously by Lindsay et al., (1984).

The 24-hr pattern of circulating melatonin was determined before and at various times after transfer to the common intermediate photoperiod; representative patterns are illustrated in figure 7 . In all cases, the melatonin patterns were found to be appropriate to the photoperiod, with levels being low during the day and elevated at night. Thus, the phase and duration of the elevation in melatonin were the same in both groups of ewes exposed to the common intermediate photoperiod, yet opposite reproductive responses were produced. This leads to the hypothesis that the nature of the change in its secretory profile constitutes a critical feature of the melatonin signal. Although this hypothesis remains to be tested formally, it has important ramifications with regard to the characteristics of the melatonin pattern that provide the code for daylength. These implications are now described in the final section of this report.

\section{Synopsis.}

As pointed out at the start of this report, there are two major conceptual models to explain how the rhythmic secretion of melatonin transduces photoperiodic information into a reproductive response, the duration of elevated melatonin secretion and the phase of this elevation relative to a circadian rhythm of sensitivity to melatonin. Available evidence in the ewe is most compatible with there being a critical role for duration. Nevertheless, the study just described in figure 7 indicates that the duration hypothesis cannot be applied in an absolute sense, for it is clear that a given melatonin duration can lead to opposite reproductive responses. The photoperiodic signalling system, therefore, is considerably more complicated than commonly envisaged. In particular, if we can accept an important role for duration, then it must be duration relative to the prior melatonin pattern, and thus whether the nightly melatonin rise is lengthening or shortening. Recent observations in the Djungarian hamster (Hoffmann et al., 1986) also support this view, thus suggesting that this concept may be broadly applicable to those mammals which utilize the circadian rhythm of melatonin secretion to adjust the timing of their seasonal reproductive cycles. In the ewe, this timekeeping process ensures an appropriate temporal relationship between an endogenous reproductive rhythm and a seasonally changing environment. 
Acknowledgements. - We thank Douglas Doop and Barbara Glover for technical assistance, Diane Belleba for preparation of the manuscript, the Standard and Reagents Core Facility for preparing assay reagents, and the Sheep Research Core Facility for maintaining the animals. The work was funded by grants from the NIH (HD-18337, HD18258), the NSF (PCM-8316364) and the I.N.R.A. of France which supported Benoit Malpaux.

Résumé. Caractéristiques du signal "mélatonine" qui fournit l'information photopériodique du moment de la reproduction chez la brebis.

Ce travail fait le point de nos études pour identifier les aspects importants de la cinétique circadienne de la sécrétion de mélatonine qui fournit la lecture de la durée du jour et contrôle la saison de reproduction de la brebis Suffolk. Les premières séries d'expériences évaluent deux modèles conceptuels du codage de la durée du jour par la mélatonine : le moment dans ce rythme circadien où la mélatonine s'élève par opposition à la durée de cette élévation au cours d'une période de $24 \mathrm{~h}$ (phase vs durée). De forts arguments ont été accumulés en faveur de l'hypothèse de la durée, tandis qu'aucun résultat ne permet d'appuyer le rôle de la phase, cependant cette hypothèse ne peut être définitivement écartée.

Une seconde série d'études met en évidence l'importance de la cinétique préalable de la sécrétion de mélatonine qui conditionne l'interprétation d'un signal donné de mélatonine. II est montré qu'une cinétique fixe de sécrétion de mélatonine peut maintenir une réponse caractéristique de la reproduction seulement pendant une période de temps limitée et que cette réponse peut être prolongée par des changements appropriés dans la cinétique de mélatonine. Le changement est donc un facteur important pour le signal de la mélatonine. De plus, la nature de la variation de la mélatonine apparaît de grande importance, particulièrement si la durée de l'élévation nocturne augmente ou diminue. Ainsi, une modification de la photopériode peut provoquer soit l'induction, soit l'arrêt de l'activité caractéristique de la reproduction selon que la modification se traduit par une diminution ou par une augmentation de la durée du jour. Ceci a d'importantes répercutions sur les manipulations de la photopériode pour les espèces qui utilisent la durée du jour pour programmer leur cycle de reproduction saisonnière.

\section{References}

ALMEIDA O. F. X., LINCOLN G. A., 1984. Reproductive photorefractoriness in rams and accompanying changes in the patterns of melatonin and prolactin secretion. Biol. Reprod., 30, 143158.

ARENDT J., SYMONS A. M., LAUD C., 1981. Pineal function in the sheep : evidence for a possible mechanism mediating seasonal reproductive activity. Experientia, 37, 584-586.

BITTMAN E. L., 1984. Melatonin and photoperiodic time measurement : evidence from rodents to ruminants, 155-192. In The pineal gland, Ed. R. J. REITER. Raven Press, New York.

BITTMAN E. L., KARSCH F. J., 1984. Nightly duration of pineal melatonin secretion determines the reproductive response to inhibitory day length in the ewe. Biol. Reprod., 30, 585-593.

BOYD I. L., 1986. Photoperiodic regulation of seasonal testicular regression in the wild European rabbit (Oryctolagus cuniculus). J. Reprod. Fert., 77, 463-470.

CARTER D. S., GOLDMAN B. D., 1983. Antigonadal effects of timed melatonin infusions in pinealectomized male Djungarian hamsters (Phodopus sungorus sungorus): duration is the critical parameter. Endocrinology, 113, 1261-1267. 
DOWELL S. F., LYNCH G. R., 1987. Duration of the melatonin pulse in the hypothalamus controls testicular function in pinealectomized mice (Peromyscus leucopus). Biol. Reprod., 36, 1095 1101.

GOLDMAN B. D., CARTER D. S., HALL V. D., ROYCHOUDHURY P., YELLON S. M., 1982. Physiology of pineal melatonin in three hamster species, 210-231. In Melatonin rhythm generating system. Ed. D. C. KLEIN, Karger, Basel.

GOLDMAN B. D., DARROW J. M., YOGEV L., 1984. Effects of timed melatonin infusions on reproductive development in the Djungarian hamster (Phodopus sungorus). Endocrinology, 114, 2074-2083.

HOFFMANN K., ILLNEROVA H., VANACEK J., 1986. Change in duration of the nighttime melatonin peak may be a signal driving photoperiodic responses in the Djungarian hamster (Phodopus sungorus). Neurosci. Lett., 67, 68-72.

HORTON T. H., 1984. Growth and development of male Microtus montanus is affected by the prenatal photoperiod. Biol. Reprod., 31, 499-504.

KARSCH F. J., BITTMAN E. L., FOSTER D. L., GOODMAN R. L., LEGAN S. J., ROBINSON J. E., 1984. Neuroendocrine basis of seasonal reproduction. Rec. Progr. Horm. Res., 40, 185-232.

KARSCH F. J., BITTMAN E. L., ROBINSON J. E., YELLON S. M., WAYNE N. L., OLSTER D. H., KAYNARD A. H., 1986. Melatonin and photorefractoriness: loss of response to the melatonin signal leads to seasonal reproductive transitions in the ewe. Biol. Reprod., 34, 265274.

KENNAWAY D. J., SANFORD L. M., GODFREY B., FRIESEN H. G., 1983. Patterns of progesterone, melatonin and prolactin secretion in ewes maintained in four different photoperiods. $J$. Endocrinol., 97, 229-242.

LEGAN S. J., KARSCH F. J., 1980. Photoperiodic control of seasonal breeding in ewes : modulation of the negative feedback action of estradiol. Biol. Reprod., 23, 1061-1068.

LEGAN S. J., KARSCH F. J., FOSTER D. L., 1977. The endocrine control of seasonal reproductive function in the ewe : a marked change in response to the negative feedback action of estradiol on luteinizing hormone secretion. Endocrinology, 101, 818-824.

LINCOLN G., 1980. Photoperiodic control of seasonal breeding in rams - the significance of shortday refractoriness, 283-286. In Proc. VI int. Congr. Endocrinol. Eds I. A. CUMMING, J. W. FUNDER \& F. A. O. MENDELSOHN, Austr. Acad. Sci. Canberra.

LINCOLN G. A., 1984. The pineal gland. In Reproduction in mammals, Book 3, 2nd ed., Hormonal control of reproduction, pp. 52-75, Eds C. R. AUSTIN \& R. V. SHORT, Cambridge Univ. Press, Cambridge.

LINDSAY D. R., PELLETIER J., PISSELET C., COUROT M., 1984. Changes in photoperiod and nutrition and their effect on testicular growth of rams. J. Reprod. Fert., 71, 351-356.

MALPAUX B., ROBINSON J. E., BROWN M. B., KARSCH F. J., 1987. Reproductive refractoriness of the ewe to an inductive photoperiod is not caused by inappropriate secretion of melatonin. Biol. Reprod., 36, 1333-1341.

MALPAUX B., MOENTER S. M., WAYNE N. L., WOODFILL C. J. I., KARSCH J. F., 1988a. Reproductive refractoriness of the ewe to inhibitory photoperiod is not caused by alteration of the circadian secretion of melatonin. Neuroendocrinology (in press).

MALPAUX B., ROBINSON J. E., BROWN M. B., KARSCH F. J., 1988b. Importance of changing photoperiod and melatonin secretory pattern in determining the length of the breeding season in the Suffolk ewe. J. Reprod. Fert., 83 (in press).

REITER R. J., 1980. The pineal and its hormones in the control of reproduction in mammals. Endocr. Rev., 1, 109-131.

ROBINSON J. E., FOLLETT B. K., 1982. Photoperiodism in Japanese quail : the termination of seasonal breeding by photorefractoriness. Proc. r. Soc. Lond. B., 215, 95-116.

ROBINSON J. E., KARSCH F. J., 1984. Refractoriness to inductive day lengths terminates the breeding season of the Suffolk ewe. Biol. Reprod., 31, 656-663.

ROBINSON J. E., KARSCH F. J., 1987. Photoperiodic history and a changing melatonin pattern can determine the neuroendocrine response of the ewe to daylength. J. Reprod. Fert., 80, 159165.

ROBINSON J. E., KARSCH F. J., 1988. Timing the breeding season of the ewe : what is the role of daylength? Reprod. Nutr. Dévelop., 28, 365-374. 
ROBINSON J. E., WAYNE N. L., KARSCH F. J., 1985. Refractoriness to inhibitory day lengths initiates the breeding season of the Suffolk ewe. Biol. Reprod., 32, 1024-1030.

ROLLAG M. D., O'CALLAGHAN P. L., NISWENDER G. D., 1978. Serum melatonin concentrations during different stages of the annual reproductive cycle in ewes. Biol. Reprod., 18, 279-285.

STETSON M. H., WATSON-WHITMYRE M., 1986. Effects of exogenous and endogenous melatonin on gonadal function in hamsters. J. Neural Transm., 21 (Suppl.), 55-80.

STETSON M. H., SARAFIDIS E., ROLLAG D. M., 1986a. Sensitivity of adult male Djungarian hamsters (Phodopus sungorus sungorus) to melatonin injections throughout the day : effects on the reproductive system and the pineal. Biol. Reprod., 35, 618-623.

STETSON M. E., ELLIOTT J. A., GOLDMAN B. D., 1986b. Maternal transfer of photoperiodic information influences the photoperiodic response of prepubertal Djungarian hamsters (Phodopus sungorus sungorus). Biol. Reprod, 34, 664-669.

TAMARKIN L., HOLLISTER C. W., LEFEBVRE N. G., GOLDMAN B., 1977. Melatonin induction of gonadal quiescence in pinealectomized golden hamsters. Science, 198, 953.

WATSON-WHITMYRE M., STETSON M. H., 1983. Simulation of peak melatonin release restores sensitivity to evening melatonin injections in pinealectomized hamsters. Endocrinology, 112. 763-765.

WAYNE N. L., ROBINSON J. E., MALPAUX B., KAYNARD A. H., KARSCH F. J., 1986. Is exposure to a short-day pattern of melatonin every night necessary to elicit reproductive induction and photorefractoriness in the ewe ? Biol. Reprod., 34 (Suppl. 1), 239.

WAYNE N. L., MALPAUX B., KARSCH F. J., 1988. How does melatonin code for day length in the ewe : duration of nocturnal melatonin release or coincidence of melatonin with a lightentrained sensitive period? Biol. Reprod. (in press).

YELLON S. M., BITTMAN E. L., LEHMAN M. N., OLSTER D. H., ROBINSON J. E., KARSCH F. J., 1985. Importance of duration of nocturnal melatonin secretion in determining the reproductive response to inductive photoperiod in the ewe. Biol. Reprod., 32, 523-529. 